\title{
Feasibility Study of Pattern of Mentoring Personnel Training in Social Work in Ethnic Area
}

\author{
Xiangui Luo* \\ Guizhou MinZu university of China, Guiyang GuiZhou China
}

Keywords: ethnic area, social work, talents mentoring

\begin{abstract}
China is a multinational country, most of minority groups live in far frontier zone or undeveloped mountainous area,the economic and social development lags behind, low level of public services and social welfare services.At present there are multiple pressure such as unsatisfied needs of ethnic group due to traditional service system, and unpleasant effects of professional social work,also non-sustainability.To solve cultural identity,ethnical belonging,economic income and life adjustment,so outside worker can walk into and stay in the life circle ,it's a feasible method that take mentoring personnel training in social work to develop social work talent who is ethnic minority.
\end{abstract}

\section{Introduction}

May $17^{\text {th }}$ 2016, Xi jinping ,the president of the People's Republic of China ,made a new claim on development of Philosophy and Social Science at forum during his speech.the year 2016 is exactly 10 year after the Central Committee of the Communist of China(CPC) came up with "build up great social work talent team”,In the past 10 years, our team have gone through the phase of rapid development, we have reached multiple and pretty good quality level, which contains junior college degree、 bachelor degree、master degree.At the end of 2014, we have 310 colleges and universities recruit undergraduate major in social work nationwide、 70 higher vocational colleges recruit junior college student major in social work 104 universities (research institutions) recruit master students major in social work.At April 2015, assistant social workers and social workers with certificates has reached 159 thousands, the number of social work talents of all kinds has breakthrough $0.4 \mathrm{millon}^{1}$ 。 Review June $25^{\text {th }}$ 2010, Member of the Standing Committee of the Political Bureau of the CPC Central Committee,vice premier of the state council、liangyu Hui claims that it have great significance on protecting regional stability of ethnic groups and promoting the common prosperity and development of all ethnic groups to develop social work in ethnic region.7 years goes by, how is social work development in minority ethnic areas? The answer is: It's pretty bad that social work and talent team development in minority ethnic areas, and it has pretty big distance to our aim.In recent years, only several experts and scholars went into ethnic region operates short-term services in the form of Research project,services bought by government and Disaster relief.It's a vital issue to discuss that how to develop a professional social work talent team which can meet the

* Article are result of study on ethnic social work talent development mechanism by research project of Humanities and Social Sciences in Institutions of higher learning of Education Department in Guizhou

Brief introduction of the author:Xiangui Luo,,female,Guiyang, Guizhou China,vice professor of GuizhouMinZu university

Website of Ministry of Civil Affairs:The status of Chinese social work development and work focus in 2015(April 22th 2015) 
ethnic region's demand and fill up traditional administration also satisfied all the need of minority groups to face complicated foreign environment and domestic growing ethical social contradictions. There are 55 ethnic minorities in China,most of them lives in remote backward region,they were influenced by culture location、resources etc, lack of information,public needs can not be satisfied, low monolithic social welfare level, some of their material and spiritual life standards roundtrip between poor and anti-poor.Traditional administration system is unitary, the kind of services is limited, the needs of minority groups can not be satisfied.It's urgent to develop a ethnic minority's social work talent team who serve and stand for themselves, traditional mentoring pattern perfectly conform to features.This method is new kind of pattern to develop talent in minority areas that worthy to try.

\section{The Necessity of Mentoring social work talent training}

At present, during advancing works in minority areas, we have many policies contains politics,economy,culture for ethnic minority at country level,in areas where ethnic minorities are more concentrated, the policy of regional national autonomy also be carried out.But practical work in minority areas,the basic implementation of the national unified administrative management service system, in the process of events often rise to the relationship between ethnic issues in national political level, ignore the uniqueness of each nation's own general and minority culture.There are 55 ethnic groups, each nation has different basic language, culture, customs, religion, morality and life habits, some people also have their own ethnic minority languages and management rules and regulations, have strong group identity and national ownership in the national culture, ethnocentrism is strong. The traditional only pay attention to the political dimension of national administrative mode, and foreign social workers with cultural sensitivity intervention in ethnic minority areas is difficult to effectively carry out the service in the minority to provide help and services.

Cultural identity, ethnic conflict and contradiction of ownership and "ethnocentrism" and a series of culture and civilization will affect foreign social workers work in minority areas. Everyone from birth to growth in the Asian culture, formed a set of cultural identity, values and "other" evaluation standard, in later life, the same values that carry out the action criteria under the guidance,and social workers are no exception. Although the professional requires that each social worker must abide by the professional ethics and moral , must maintain the cultural diversity, must hold the "cultural sensitivity" work as a principle, and to the "other" non acceptance of rejection. But in fact,during work social workers can not be stripped of their culture, no culture shock and conflict. Every social worker also grew up in different subcultures, have a certain cultural background, ideas and value standard, and these also take influence on their actions. Especially work in national service, when there is a strong gap since the culture and the "other" culture, social work can always keep the price remains the same value idea and the behavior way and the "other" culture.Like Chinese professor $\mathrm{Gu}$ Xuebin of Hongkong said, theoretically,we are alert,but in actual operations,we often fall into traps of professional knowledge.Just like "cultural illiteracy"in anthropology.It makes us lose the cultural sensitivity during the promote the project so the project will face many challenges. Meanwhile the ethnic minority,lives in remote districts,influenced by information,languages,location,transports, hardly have contact with other groups and people,so it's normally short of common understandings,there maybe exclusive cultural centralism.Even if social workers can accept minority ethnic groups equally, let ethnic groups to fully accept foreign social work is very difficult,even what harder is that let the outsider people provide services and help. In Yushu China 2010,social workers try to go to the disaster area through disaster social work, crisis intervention and other professional methods to help the bereaved minority people , but the fact is that social workers almost can't accepted by the local people, no need to say that effectively carry out the work in ethnic groups. They only take the normally wany that local people always do - a few days and nights to kneel to pray to the gods to bless, to say goodbye to people lost loved ones and 
living comfort.

It's hard to absorb social worker into minority areas,It is harder that making them stay and long-term work,due to a series of realistic issue such as regional difference,income level and habits and customs. Sever brain drain of social work talent is a common issue of China. Statistics suggest that the percentage social work brain drain of Shenzhen form 8.2\%(2008)increase to 22.2\%(2014). In Beijing,2015,nanli community of Donghuali City, that number goes to 25\%.This kind of problem happens in mature places, remote ethnic region are lot of worse, they not only face the brain drain, also brain inlet.On the one hand, most of the minority nationalities in remote border areas or backward mountainous areas, traffic, communication, medical, education and other infrastructure is very backward, and compared to the eastern and coastal areas, the work condition is relatively difficult, there is no reason and conditions to attract talent to social work.On the other hand, in the diet, there are huge differences between them on religious beliefs and living mode. The ethnic Han and other ethnic social workers is difficult to adapt and long-term continue to stick to it.Third, the development of social work in ethnic minority areas is lagging behind, unlike in the coastal and eastern developed regions, different regions are established in line with the characteristics of their social work regulations, clear social workers salary standard, mature service model and professional supervision team. But ethnic areas, system and mechanism, compensation standard and mode of operation are in the blank. To carry out ethnic areas of social work, no reference model, need to start from zero, the risk and difficulty are tremendous. The most of college students are more willing to stay in the city, or the civil service exam, institutions and other relatively stable occupation. Occasionally a few with passion and love for the professional, to engage in professional work in ethnic minority areas, but in the end because of low income, occupation prospect, hard to adapt and other factors, have chosen to leave or transfer.

\section{The feasibility of mentoring social work talents training}

There exists a gap between post settings and professional identity, so it is hard for social workers to continue to develop and the sustainability of government procurement services, public funding activities and research subjects is difficult to guarantee.With the further development of social reform and a series of management concepts such as small government, big society and innovation of social governance put forward, part of ethnic regions under the impetus of the party and state policies gradually began to set up social posts in public security organs, civil administration, social community and other departments to recruit graduates of professional social work.However, after they were employed, they found there was a fairly big gap between post settings and professional identity and the work revolved around "the social work" which is not much related to social work specialty, whose career prospect is divorce from professional development. In recent years, with the deepening development of social economy and reform of political economic system, government procurement services, public funding activities and research subjects which are launched in ethnic regions have increased. Some experts and scholars of colleges and universities and scientific research institutions use these opportunities with professional teams into ethnic regions to carry out social work services. Through these professional activities, the awareness and understanding of minority ethnic regions for society has improved, thus the ability of self-survival and development of minority ethnic regions has risen, which plays an important role in promoting social and economic development in ethnic regions, meeting the needs of survival and development of minority ethnic regions and embodying the fairness and justice of social welfare service.The question is that these projects have time limit, once they are finished, workers of professional teams have to evacuate in succession, which does not hatch new social work institutions, nor cultivate new talents for social work in the locality, so the activities or projects launched cannot continue and end with the withdrawal of the teams. The ministry of civil affairs in 2012 promulgated the "outlying poverty-stricken regions, frontier ethnic regions and old revolutionary regions talents support plan social work professional talents project implementation plan"(referred to as the " 'three zone' 
schemes of social workers ", from the beginning of its implementation to now for three years, the effect of which is too far away from the target.Most of the units that accept government procurement projects are schools, scientific research institutions and service organizations. They sign one -year or two-year short service contracts with the local civil affair departments, bring their own teams (professional training students as the main object) into the service units and carry out various forms of activities and services combined with their own practical conditions, with the aim of accept mid-term inspection and terminal evaluation of the local civil affair departments (contracts signed units). However, professional service workers in the course of work are changed frequently because of students' internships, institutions, other work needs and other reasons, as a result, the continuity of work and the quality of activities or services cannot be guaranteed. As soon as the contract time ends, the service is terminated immediately, so the local talent training and project incubation have failed to meet the original intentions of the project design.According to the State Personnel Board and Ministry of Civil Affair jointly issuing "social workers occupation level evaluation temporary provision”, on social workers explained that social work talents including (1) social workers who were engaged in social work for a long period and made outstanding contributions, (2) professionals who became assistant social workers, social workers and senior social workers by social work occupation qualification evaluation, (3) other personnel who specialize in social work management, teaching and research with primary and above professional technical positions.All in all, social work talents are professionals who are engaged in social work management, practice, education and research.Since social workers are a kind of professionals, professional skills and knowledge can be acquired by traditional mentoring learning and training.Mentoring also named apprenticeship, means that apprentice under the guidance of a master acquire skills and knowledge, which is an important form of occupational education.Social work talents mentoring mode in ethnic region refers to electing some national elites from ethnic region who follow professional social workers (social workers or education researchers) for a period of time (one year or more), in the "master" of professional guidance , obtain professional knowledge and skills through the theoretical study and practical training, and go into the ethnic region to carry out social work service.In the view of many practical problems of current social work talents in ethnic region, the training mode of mentoring social work personnel is the reasonable path choice of solving current social work talents in the ethnic region shortage problems, promoting social work development in ethnic regions, enhancing social welfare service of ethnic regions and realizing the harmonious development of society. As mentioned earlier, in reality, it is difficult for social workers to keep ideas in accordance with practical actions when they carry out work in ethnic regions. It is also impossible for them to keep value neutrality according to professional values, ethics and morality, and realize "the other" with cultural sensitivity. When the national belonging and cultural identity of social workers encounters "the other" strange culture in practical work, it results in cultural shock, brings great cultural conflict and pressure to social workers, and disturbs people's life in minority regions.Meanwhile, if social workers do not handle properly and bring their own culture into work, they may lead to cultural invasion.However, mentoring trained social workers will not happen. They are a member of national people; they are acquaintances who grew up in the education of the national culture whose language, life habits and religions are the same with ethnic compatriots. Even they are the elites of the nation and carry out social work service among their nation. They are respected, loved and supported by their compatriots. There had been such a thing in the Yushu earthquake in 2010. When the professional rescue work can not be carry out smoothly in the community, a team member who go to Yushu to participate in voluntary service work plays an important role so that the rescue work was finished successfully in his help.This team member is a graduate of the local area with the same cultural identity and religions with the disaster area. When he arrived in the disaster area, he prayed in their traditions with the people of the disaster area for the blessing of the gods, and gained the trust of the victims.The cost of mentoring pattern is pretty low,pertinence are strong and easy to have achievement.At present,there are two method to development social work talent in China,scientific 
education in universities and colleges or short-term training course in Neighborhood Committee.The scientific education takes a long time and costs a lot,besides, severe brain drain and hard to predict.Students receive professional educate in schools, it takes 3 or 4 years,if you decide to continue higher-level education,it takes longer time to learn scientific knowledge and skills. At school,during learning the courses, it takes large amount of educate equipment,book resources,manpower, and cooperation between administration and supplementary department.It's unpredictable that after graduation,students are willing to work as social worker,and whether they are willing to work in ethnic area. Short-term training courses are hard to ensure the effect because of short time,differences between trainees etc.Mentoring pattern combine two methods. "master"guidance one or several pupils form ethnic area, on concentrated theory training and field learning of multi domain,after 1 year or longer time, learning while working,form easy to hard ,eventually return to ethnic area and work independently. This way could shorten the time of school education time ,save the cost of manpower and material resources, and solve the problem of training effect at short-term training course,what's more important, "master" could guidance their pupil lifetime, during the work after learning, “master” not only can seen as supervisor,also can help them on their problem with professional assistance.

The social workers who was developed from mentoring pattern can stay local,and their work is stable.They sever for people who need help in their own ethnic group,it's a job ,of course ,but also it is a honor and trust.They get a stable income by serve their own people,in low-income ethnic area,it's a admiring thing that have stable income at home.These social workers, they not only represent common social worker also elite of their own group,they are someone who ethnic group trust, through their works, they can gain people's trust, promote services smoothly,what's more important,their help and services will be seen as model,it plays a certain demonstration effect, and ensure persistent of the work.

\section{Conclusion}

With the constantly development of Chinese society and economy,the differences between ethnic area and non-ethnic area are more and more obvious,social contradictions is gradually come out of water.Traditional ethnic policy of macro level and single administration no longer can satisfied the needs of survival and development of ethnic minority,and development of social economy of ethnic area.It's urgent to develop a number of native social workers to break the situation which is outside social workers' dilemma build by economy culture,custom ,believes in pattern of mentoring personnel training. This pattern is a assumption that need policy and economic support by multiparty force like government,institutions and social organization if it was needed.

\section{References}

[1] Xuebin Gu,Heqing Zhang,Xicong Yang, 《Professional restrictions and cultural illiteracy:culture issue in countryside social work practise 》[J]Sociological research, 2007(6):161-179;

[2] GangGang Shi JingLiu, 《Analysemaster-apprentice relation changes in Chinese mentoring 》,[J]Communication Vocational Education, Page $5425^{\text {th }} 2013$;

[3] ShidongXu , 《Several cogitates about ethnic social work talent 》, [J] Social work and management 15th book ; $2015 / 05$ (3) 